\title{
María Alfonso Coronel y la Casa Medina Sidonia. Dando a luz a la mujer detrás de la leyenda
}

\author{
María Alfonso Coronel and Medina Sidonia House. The \\ Woman Standing in The Shadows of Her Own Legend
}

\begin{abstract}
RESUMEN
María Alfonso Coronel nació en 1267 en el seno de una acaudalada familia noble. Fue dada en matrimonio a Alfonso Pérez de Guzmán el Bueno por Alfonso X el Sabio como premio a los servicios que este había hecho a la Corona de Castilla. María Coronel, vulgarmente llamada la del Tizón, supo administrar de manera diligente el extenso patrimonio que aportó al matrimonio como dote. Hábil corredora de negocios, ella y Guzmán consiguieron ampliar hasta límites inimaginados el patrimonio de su Casa. Fernando IV los nombró en 1297 señores de Sanlúcar de Barrameda. Los títulos y propiedades que con tanta pericia supo gestionar María Coronel sentaron las bases del futuro ducado de Medina Sidonia, el título ducal hereditario más antiguo de España. La leyenda de los esposos fue llevada a la literatura en repetidas ocasiones.

Palabras clave: María Alonso Coronel, Alfonso Pérez de Guzmán, Sanlúcar de Barrameda, Medina Sidonia, mujer heroica.
\end{abstract}

\begin{abstract}
María Alfonso Coronel was born in 1267 in the bosom of a wealthy noble family. She was given in marriage to Alfonso Perez de Guzman el Bueno by Alfonso X el Sabio, as a reward for the services he had done for Castile. María Coronel, nicknamed la del Tizón, diligently managed the vast heritage she had provided as a dowry. A shrewd broker, she expanded their heritage to unimagined limits. Fernando IV appointed them as Lord and Lady of Sanlúcar de Barrameda. The countless nobility titles and properties, nifty handled by María, built a foundation for the future Duchy of Medina Sidonia, the most ancient ducal hereditary title in Spain. Their legend was adapted to literature repeatedly.

Keywords: María Alonso Coronel, Alfonso Pérez de Guzmán, Sanlúcar de Barrameda, Medina Sidonia, heroic woman.

\section{Sumario}

1. Introducción: Eva o María - 2. María Alfonso Coronel, Señora de Sanlúcar 3. Construir un mito: María, la del Tizón. 4. La mujer heroica. 5. Conclusiones. Bibliografía. Fuentes.
\end{abstract}

\section{Introducción: Eva o María}

La percepción que pueda tenerse de cualquier individuo parte de quien es realmente y de cómo es visto por quienes lo analizan. Dicho de otra forma, considerar la persona de María Alonso Coronel desde una perspectiva meramente histórica resulta un tanto sesgado siendo como fue musa inagotable de la literatura del XVIII.

1 Universitat Jaume I, al227893@uji.es. 
Ocurre a menudo con este tipo de figuras históricas cuya fama renace a posteriori, el relato que se genera de ella es casi de igual importancia que su verdadera biografía porque aporta informaciones que de otra forma podríamos pasar por alto, como a qué actos o actitudes se dieron importancia, por qué y qué fin persiguen. A lo largo de este epígrafe se tratará de dar respuesta a qué lugar ocupaba una mujer como María Alonso Coronel en la sociedad andaluza de su tiempo y qué lugar ocupó más tarde su leyenda en la sociedad moderna procurando dar respuesta a los interrogantes que antes se planteaban: a qué se dio importancia, por qué y para qué.

Anderson y Zinsser subrayan la guerra como la circunstancia que más marcó la vida de las mujeres en el medievo. La guerra impregna todos los aspectos de la vida en esta época, tanto es así que algunos hombres se especializan en ella y la convierten en su profesión. Profesión que, como ocurría con la mayoría de oficios, se hereda entre padres e hijos. Como experimentó la propia María Coronel, la guerra que por un lado tanto cambió el devenir de muchas personas y pueblos, poco cambió los cometidos que se le toleraban. A las niñas se les enseñaba en el «oficio» de ser madre (Peñafiel, 2001: 24). Además, señala Anderson y Zinsser, con la división del Imperio de Carlomagno muere la autoridad centralizada, esto es, la tenencia de la tierra ya no retornaba al legado del señor a la muerte de cada teniente, sino que se ceñía al derecho de sucesión. Así, desde el siglo IX al XII se asiste a un sistema que establece la primacía e independencia relativa de las familias; ha nacido el concepto «linaje» (2000: 323).

María Alonso Coronel y sus contemporáneas no servían a los intereses de la guerra de manera directa. «En teoría no podían luchar, en la práctica no se les adiestraba para ello» (Anderson y Zinsser, 2000: 322). El papel de las mujeres en este marco guerrero se desdoblaba en dos. La primera y más obvia tarea era la guarda de este rango privilegiado, la custodia y dirección de la familia, la casa, el linaje o la dinastía. Dicho de otra forma, las mujeres entraban a formar parte de la sociedad guerrera en el momento en que formaban su familia, es decir, se casaban. El matrimonio les ofrecía protección y sustento, pero a la vez silencio e impotencia. «Como hijas, aceptaban los planes que la familia tenía para ella. Cuando alcanzaban la madurez, se convertían en esposas y como esposas aceptaban el matrimonio con sus desventajas y compensaciones» (Anderson y Zinsser, 2000: 311). En épocas de paz, María Alonso Coronel fue la fiel compañera de su marido; en épocas de guerra, actuó en su nombre haciéndose cargo no solo de la administración de sus tierras sino de la multiplicación de las riquezas de su Casa. Este caso ejemplifica fielmente el caso de muchas mujeres que como ella vivieron la paradoja de la vulnerabilidad y el poder. La otra labor que desempeñaban estaba, si cabe, todavía más impuesta. Ellas mismas eran tratadas como botín y trofeo de guerra. Se utilizaban como prendas, convenios o parte del negociado de paz ${ }^{2}$. La manera más directa en que se ejercía este gravamen hacia sus cuerpos era la maternidad, vista como una obligación. Las mujeres «no solo aportaban su dote al matrimonio, sino

2 Se recomienda la lectura de Nastasescu, Diana (2016): La política matrimonial de los Reyes Católicos. Repositorio Biblioteca Universitat Jaume I. URL: http://repositori.uji.es/xmlui/ handle/10234/164904 
también la donación de su cuerpo, su capacidad para perpetuar el linaje» (Anderson y Zinesser, 2000: 319).

Las estructuras de poder se aseguraban de que este sistema se perpetuase mediante la educación de los niños y niñas en sus roles. Esto se conseguía mediante las dos instituciones más influyentes en la vida de las personas: el teatro y, sobre todo, la Iglesia (Peñafiel, 2001: 29). Desde esta perspectiva, las mujeres solo podían optar por dos papeles: el de Eva, la «traidora» que subvertía su función y era castigada; o María, madre de Jesús y de la Iglesia, casta, fiel y temerosa de Dios. Que la Iglesia fue educadora en la moral que se consideraba en aquel momento la correcta es de sobra conocido. Pero más característica fue la influencia del teatro: ora María, fiel instructor y herramienta del sistema, ora Eva corruptor de la moral de los actores, actrices y el público que asistía al espectáculo. El teatro es sugestivo si convierte la vida de una persona en obra teatral, pero todavía más sorprendente si se escribe sobre la vida de un personaje histórico y se le asignan peculiaridades morales de otra época. Este es el caso de María Alonso Coronel, castellana que vivió en la Andalucía medieval y que es llevada al teatro en la España del siglo XVIII.

A lo largo de este artículo analizaremos la figura de María Alfonso Coronel y trataremos de perfilar su legado más allá del mito que se formó en torno a ella. Para ello cotejaremos su biografía y la fábula que se le atribuye atendiendo a qué distintivos de María se seleccionaron a la hora de forjar su leyenda, por qué y con qué fin.

\section{María Alfonso Coronel, Señora de Sanlúcar}

María Alfonso Coronel nació en Castilla en el año 1267 hija de Fernán González Coronel y de Sancha Íñiguez de Aguilar³. Los Coronel pertenecían a un acaudalado linaje de origen gallego que se sitúa en Castilla a partir del siglo XII, cuando Don Pedro Coronel participa en la conquista de Portugal (Liañez y Valderrama, 2004: 559-572). Al nacimiento de María Coronel reinaba en Castilla Alfonso X el Sabio. La situación en la península Ibérica en aquel momento giraba en torno a la conquista cristiana de Al-Ándalus. En el siglo XIII los reinos cristianos habían pactado su acción conjunta para hacer frente al gobierno de las Taifas; la alianza ya había probado su éxito en la conocida Batalla de Navas de Tolosa (1212). El reino andalusí debilitado y fragmentado no resistía un ataque cada vez más organizado. Otra de las batallas decisivas para el triunfo de los reyes cristianos fue la del Estrecho (12741350), territorio de los Benimerines.

Don Alonso Pérez de Guzmán que más tarde se casaría con María Coronel, era vasallo del sultán meriní Abu Yusuf Yaqub ibn Abd Al-Haqq. El sultán estaba enfrentado con Alfonso X desde el ataque cristiano en Salé4. Con todo, Guzmán consiguió que establecieran una tregua para que el rey castellano pudiera enfrentarse

3 Real Academia de la Historia [en adelante RAH], Colección Salazar y Castro [en adelante SC] 9/24 Ilustraciones de la Casa de Niebla, p. 94 «los quales Alfonso Fernández y su muger Sancha tuvieron una hija y un hijo(...)»

4 Salé es una ciudad marroquí de la costa Atlántica que limita con Rabat en la orilla norte de la desembocadura del río Bu Regreg. 
a su hijo, el infante Sancho, quien a la muerte del primogénito de Alfonso X pretendía ser sucesor a la Corona pese a que los derechos sucesorios no lo señalaban a él como heredero. Como premio a la exitosa mediación de Guzmán, el Alfonso X le ofreció en matrimonio a María Alfonso Coronel. La vulgarmente apodada del Tizón se casó con don Alfonso Pérez de Guzmán en 1282. Parte del premio, la dama, aportaba un valioso bloque de propiedades como dote que ayudó a asentar los cimientos del patrimonio de la Casa:

La viña de Bolaños en Castilla y unos pueblos en el reino de Galizia y de León, y unas heredades en el reino de Portogal y çiertos pares de açeñas en Xerez en el río de Guadalete y en el Axarafe de Sevilla. Le mandaron el lugar de Bollullos con sus heredades y á Torrijos con sus olivares, y a Robaína con sus olivares y tierras de Montañina y del Barroso y de Laina y unas casas á Sevilla a la collaçion de San Miguel çerca de San Vicente, y demás desto dineros y joyas. ${ }^{5}$

En 1284 murió Alfonso X y subió al trono el Sancho IV razón por la cual Guzmán tuvo que exiliarse a Fez al amparo del sultán meriní acompañado de su espo$\mathrm{sa}^{6}$. Pronto empezaron a hacer fortuna y María aprovechó su condición de mujer para sustraer riquezas del Magreb sin llamar la atención ${ }^{7}$. Rafael Benítez en su coloquio «Cautivas a ambos lados del Mediterráneo» subrayaba esta práctica como muy común entre la población de la península. Algunos cristianos perseguidos o renegados con la religión - o la política, como es el caso- se marchaban al Norte de África donde las más de las veces conseguían alcanzar altos cargos. «Es costumbre de los figosdalgo de castilla que quando no son bien tratados de sus señores que se vayan á buscar fuera della quien más bien les faga». ${ }^{8}$. Una vez amasadas sus fortunas, algunos volvían a la península Ibérica. Las mujeres eran frecuentemente las encargadas de extraer las riquezas de una orilla a otra. Al parecer, la percepción ingenua y vulnerable que se tenía de ellas jugaba en estos casos a su favor ${ }^{9}$. Parece evidente que visitó regularmente a su marido en la otra orilla — seguramente para extraer más riquezas - porque toda su descendencia nació entre 1285 y 1290. Teniendo en cuenta la cantidad de adquisiciones que hizo mientras Guzmán estaba en Fez y el hecho de que algunos historiadores fechen el suceso del Tizón en 1291, cuando María Coronel apagó su deseo sexual en ausencia de su marido desfigurando sus genitales con un tizón ardiente ${ }^{10}$, se cree tener argumentos suficientes para afirmar que María Coronel se estableció en Sevilla en casa de su madre entre 1285 y 1286.

5 RAH, SC 9/24 Ilustraciones de la Casa de Niebla, p. 94.

6 Ibídem, p. 107 «[...]don Alfonso Pérez pasó Algueciras y llevó consigo a su muger doña María Alfonso Coronel(...)».

7 Ibidem, p. 113 «[...]cautela con que usó a su muger doña María de Coronel a España con la mayor parte de esta de moneda $[\ldots] »$.

8 Ibídem, p. 60.

9 Estos datos fueron comentados por el historiador Rafael Benítez en el coloquio «Cautivas a ambos lados del Mediterráneo» en el XIV Seminario Monográfico de Historia Moderna del grupo HisMoAL en colaboración con el Instituto de Estudios Feministas Purificación Escribano celebrado el 13 de diciembre de 2016 en la Universidad Jaime I, Castellón.

10 Este hecho es comentado en todas las crónicas, la más remota es la escrita en el siglo XVI por Pedro Barrantes Illustraciones de la Casa de Niebla. La referencia completa se detalla en el apartado Fuentes y Bibliografía. 
Tuvieron dos hijos y dos hijas: Juan Alonso Pérez de Guzmán (1285-1351) ${ }^{11}$, Pedro Alonso Pérez de Guzmán (1286-1294); Leonor Pérez de Guzmán y Coronel (1287-1341); e Isabel Pérez de Guzmán (c. 1290-?) ${ }^{12}$.

Con el dinero que hicieron en Marruecos, María amplió las propiedades de su Casa con la compra de más olivares en el Aljarafe y algunas casas en Sevilla, en el puerto de mar junto al Algarve de Portugal, en Alaraz y Santiponce. Compró la villa de Ayamonte y su castillo sobre el Guadiana, Lepe, La Redondela (Isla Cristina), el Donadío de Ventosilla (hoy cortijo situado entre Sanlúcar y Jerez), el Donadío de Alixar (cortijo entre Sanlúcar y Jerez), el Vado de las Estacas (Alcalá del Río) y la mitad de la villa y castillo de El Puerto de Santa María y la dehesa de Vilaraña (en El Puerto de Santa María) ${ }^{13}$. Anderson y Zinsser recuerdan la notable labor que las mujeres realizaron como corredoras de los negocios de sus familias. De hecho, apuntan a que aquellas Casas en las que las mujeres tomaron las riendas de la gestión y administración del patrimonio en ausencia de sus maridos fueron las que más prosperaron de la época y, es más, recuerdan las autoras que gracias a ellas estos linajes pudieron perpetuar su poder e influencia a lo largo de los siglos venideros (2000: 319).

Si Pérez de Guzmán volvió a Sevilla en 1292 o 1293 es un tema sobre el que las historiadoras no acaban de ponerse de acuerdo. Isabel Galán sostiene que Alfonso Pérez volvería a reunirse con María en 1293, tras la batalla de Tarifa, llamado por el rey Sancho IV como gobernador del sitio por su conocimiento sobre los merenís (1988: 46). Por su parte, Luisa Isabel Álvarez de Toledo defiende que Guzmán sí habría participado en la toma de Tarifa en 1292 y que por alguna razón fue silenciado en las crónicas (1994: 12). Sea como fuere, en 1294 se produce el legendario episodio en que el infante don Juan, aliado con los benimerines y los nazaritas para arrebatarle el trono a su hermano Sancho IV, amenazan la plaza de Tarifa. El infante don Juan y sus aliados habrían secuestrado al hijo menor de Guzmán, de ocho años, y le habrían chantajeado con su vida para que les devolviese Tarifa. Lejos de ceder, Pérez de Guzmán lanzó un cuchillo desde las murallas de la fortaleza para que mataran con él a su propio hijo, Pedro Alonso Pérez de Guzmán y Coronel. Aparte del suceso legendario, Guzmán aseguró la defensa de toda la zona andaluza del estrecho de Gibraltar y ayudó en el proceso de repoblación cristiana.

El rey Sancho para premiar su servicio le prometió el señorío de Sanlúcar, que le fue cedido finalmente por merced de su hijo Fernando IV en $1297^{14}$ pues Sancho murió apenas un año más tarde del suceso tarifeño, en 1295. Se trata de un privilegio rodado que se le otorgaba a Alonso Pérez de Guzmán, alcaide del castillo de Tarifa, la villa de Sanlúcar de Barrameda «con todos sus pobladores, términos, perte-

11 RAH, SC 9/24 Ilustraciones de la Casa de Niebla, p. 109

12 Fundación Medinaceli: http:/ / www.fundacionmedinaceli.org/casaducal/fichaindividuo.aspx?id=4818

13 RAH, SC 9/24 Ilustraciones de la Casa de Niebla, p. 115 «....] pero si mediante este tiempo salía a venderle alguna villa o eredad ansi del rey como del particular ella lo sabía a comprar [...]»

14 Archivo Medina Sidonia [en adelante AMS] Fondo Medina Sidonia [en adelante MeS] AGFCMS, leg. 909, doc. 03: Privilegio Real de Fernando IV concediendo a Alonso Pérez de Guzmán la villa de Sanlúcar de Barrameda. 
nencias, pechos $y$ derechos ${ }^{15}$ entre los que se encontraban las torres de Rota, Regla (Chipiona) y Trebujena. Poco tiempo después, Fernando IV vuelve a expedir otro privilegio con el que cede las almadrabas de Conil, una aldea que Guzmán habría ayudado a poblar y Chicalana, aldea despoblada que los señores de Sanlúcar se encargaron de poblar. En 1307 recibieron el señorío de $\operatorname{Vejer}^{16}$, este se le daba a cambio de las aldeas de Zafra y Falconera (Extremadura) y de un préstamo que le habrían hecho al rey de 56.000 doblas de oro. Por otro préstamo que la Corona no pudo devolver el rey Fernando IV les otorgó el señorío sobre Marchena y una retención de las rentas de Medina Sidonia. En 1295 se habría adquirido también el puerto de Santa María al almirante Benedetto Zaccaria ${ }^{17}$ a cambio de la defensa y custodia de la zona entre el desembarco del Guadalquivir y el Estrecho. Con estos privilegios se prueba la fortaleza de la nobleza en la edad Media en contraste con la mala situación de la Corona. Esta se veía obligada a recurrir a préstamos que en ocasiones no podía devolver para continuar con sus políticas guerreras de conquista y la administración de unos reinos en vías de construcción.

Guzmán murió en batalla en 1309 sin dejar testamento. María Alfonso Coronel, viuda, con cuarenta y dos años se queda encargada de la mitad de las propiedades de la Casa, la otra mitad fue a parar al segundo señor de Sanlúcar, su hijo don Juan Alonso. Para aquel entonces el patrimonio de la Casa se extendía por todo el sur peninsular convirtiendo a los señores de Sanlúcar en la familia noble más importante de Sevilla y Andalucía. Desde ese momento no hay constancia de nuevas adquisiciones para la Casa de María Alfonso Coronel. Si bien fue una excelente corredora de los negocios familiares este hecho corrobora que actuó siempre en nombre de su marido, lo cual no desmerece su habilidad para acordar ofertas comerciales y dirigir el patrimonio familiar. Esta última tarea la llevó a cabo hasta su muerte en 1330. Según los textos, destinó todos los años un cuarto de su hacienda al mantenimiento de la casa y sus criados; otro cuarto se lo daba a sus hijos e hijas; otro a los pobres, la mayoría criados suyos; y otro cuarto lo empleaba en comprar las heredades cada año ${ }^{18}$. Dedicó los veinte años de viudez a participar y sufragar obras caritativas y visitar hospitales como se puede deducir del tono de su testamento y en lo que se refleja en la crónica de Barrantes Maldonado.

Antes de morir reunió a sus hijos y repartió su hacienda, «reservando para mi parte de la hazienda para cumplimiento de mi ánima y descargo de mi conciencia» ${ }^{19}$. Así dio a su hijo don Juan Alonso la heredad de Monteagudo y algunos olivares y tierras de pan. A doña Isabel le asignó la villa y castillo de Ayamonte, Bollullos y Montanina, aunque más tarde su hermano rescataría para sí estos dos últimos lugares. A doña Leonor le dio la mitad del Puerto de Santa María y mitad dehesa de Vilaraña ${ }^{20}$.

15 AMS, MeS, AGFCMS, leg. 888, doc. 09: Privilegio Real de Fernando IV concediendo a Alonso Pérez de Guzmán la villa de Vejer de la Frontera.

16 Ibidem.

17 Zaccaria habría dirigido el ataque naval que ayudó al rey Sancho IV a conquistar Tarifa en 1292.

18 RAH, SC, 9/24: Ilustraciones, p. 230-231.

19 Ibídem, p. 232.

20 Ibídem, p. 232-233. 
En noviembre de 1330 una grave enfermedad aquejaba la salud de una ya mayor María Alfonso Coronel, por eso llamó a sus hijos para que fueran testigos y mandó escribir su testamento ${ }^{21}$. Mandó ser enterrada cerca de su marido en el monasterio de San Isidro ${ }^{22}$ (Santiponce) y destinó 20 marcos de plata a la decoración de los sepulcros de ella y de su marido con lámparas, cálices y otros objetos ${ }^{23}$. Mandó que se destinaran 760.000 maravedíes en obras caritativas: misas, donaciones a hospitales, a criados y criadas, a amas de cría, a la liberación de cautivos cristianos y al casamiento de huérfanas ${ }^{24}$. Legó al monasterio de Santiponce las tierras colindantes que habría adquirido ella años antes así como 40 marcos de plata. Además mandó que con ese dinero se celebraran al día veinte misas, diez a la memoria de don Alfonso Pérez de Guzmán y otras diez a su memoria ${ }^{25}$. También ordenó la construcción de un hospital para pobres en los dominios del monasterio que debía ser llevado por los monjes con las rentas que obtuvieren de su recién legada hacienda y para ello instaba a la vigilancia cuidadosa de sus hijos e hijas para que su voluntad fuera hecha ${ }^{26}$.

Dio a su nieto don Fernán, hijo de doña Isabel, 300.000 maravedíes para la ayuda de su caballería ${ }^{27}$ y dotó a Juan Ortega, esposo de una hija ilegítima de Guzmán el Bueno llamada Teresa, otros cientos maravedís como dote de la muchacha que se habría casado con Ortega hacía pocas semanas. A su hermano don Juan Fernández y a su sobrino, el hijo de este, legaba sus villas en Galicia, Portugal, León y Castilla y la villa y castillo de Bolaños ${ }^{28}$.

Aparte de las reparticiones que ya había hecho en vida, dio la casa en que ella vivía a su hijo don Juan Alonso a quien, además, le perdonó las deudas que habría contraído para la defensa de la cristiandad. A Isabel dejó las viñas de Jerez y tierras en Guadalete junto con 500.000 maravedís que sacara de las rentas de Medina Sidonia ${ }^{29}$.

A Leonor le legó el donadío de Ventosilla ${ }^{30}$, la mitad de Torrijos y la mitad del Puerto de Santa María, completando así las medias donaciones que habría hecho para su dote en casamiento con Ponce de León ${ }^{31}$.

Nombró de albaceas a su hermano, a sus hijas Isabel y Leonor, a su hijo don Juan, a su comadre y a su sobrino don Alonso Fernández ${ }^{32}$. A ellas y ellos mandó

21 AMS, MeS AGFCMS, leg. 910, doc. 05: Testamento de María Alfonso Coronel. El testamento se conserva en buen estado, está escrito sobre pergamino de 560 × $622 \mathrm{~mm}$ en letra gótica albalaes con tinta de color pardo. Está disponible para su consulta en el archivo Medina Sidonia (Cádiz).

22 Ibídem «[...] e mando que dieren tierra al mi cuerpo en el monasterio de Santo Esidro que al dicho don Alfonso Pérez my marido [...]».

23 Ibídem «beinte marcos para lamparas la una para [...]».

24 Ibídem «E mando a doña María ama de Joahn Alfonso mi fijo [...]».

25 Ibídem «E mando a los frayles del dicho monasterio de Santiponce de Sevylla...».

26 Ibídem "para los enfermos públicos de Sevylla...».

27 Ibídem «[...] e mando a don Fernán mi hijado, fijo de don Fernando de Ponce y de doña Ysabel mi fija [...]».

28 Ibídem «Portogal e con Galisia e con la villa e castello de Botaños [...]».

29 Ibídem «a doña Ysabel do las fincas e vinnas en Xeres [...] e dominios que hay al río Guadalete...».

30 Ibídem «el mayorazgo de Bentosilla que yo do a la dicha doña Leonor...».

31 Ibídem «a doña Ysabel mi fija la meytad da Bolullos e da montanyna [...] a a doña Leonor mi fija la meytad del puerto de Santa María [...]».

32 AMS, MeS AGFCMS, leg. 910, doc. 05: Testamento de María Alfonso Coronel «E destos fago mys albaceas $[\ldots] »$. 
vender las casas que hiciera falta para saldar las deudas que pudiera tener y dispuso que el resto de sus dineros y joyas fueran repartidos a sus hijos e hijas por igual ${ }^{33}$.

\section{Construir un mito: María, la del tizón}

María Coronel entró en la historia como arquetipo de mujer al servicio de su familia, de Dios y de su país. En el siglo XVIII y XIX la literatura rescata a María Alonso Coronel y a su esposo Alfonso Pérez de Guzmán como prototipo de personas heroicas, cada cual en su ámbito. El hecho de que sus vidas fueran hechas leyenda desde un principio y de que la literatura romántica decimonónica usase sus figuras tan reiteradamente dificulta la tarea de la historiadora a la hora de discernir qué hay de verdadero y de ficticio en la historia de los primeros señores de Sanlúcar.

Como complicación añadida debemos señalar la existencia de diversas marías Coronel, todas notables y más o menos contemporáneas. Por una parte este factor complica el trazado de un árbol genealógico, pero por otro da cuenta de se trata de una estirpe cuyas féminas llevaron a cabo un papel activo y significativo en la historia ${ }^{34}$. Dicho sea de paso las otras marías Coronel fueron: María Fernández Coronel, aya de la reina María de Molina y tutora de la infanta Isabel, despuntó en su papel de asesora y agente diplomático, fue la abuela de la María Coronel a que se refiere este artículo; y María Fernández Coronel, apodada La de Sevilla, casada con Juan de la Cerda (Marchant, 2013: 3-5). La historiografía también mitifica a esta figura como paradigma de mujer casta y fiel que se quemó la cara con aceite hirviendo para desfigurar su rostro y que el rey Pedro el Cruel perdiera su interés en ella, ya viuda de su esposo (Segura, 2002: 5).

María Alonso Coronel por su parte también habría recibido el apodo de La del Tizón por motivos que ya se han comentado en el epígrafe anterior. Estos hechos aparecen en las crónicas de la época y también de las posteriores ${ }^{35}$, no se puede comprobar hasta qué punto son verídicas y aunque no sean de gran relevancia histórica sí que da cuenta del enfoque que daban los cronistas en la redacción de la vida de mujeres ilustres. Sea como fuere, las mujeres de la Casa Guzmán y Coronel fueron veneradas durante el Renacimiento como modelo de mujer a seguir; fieles a sus maridos, a su patria y temerosas de Dios. Uno de los textos a subrayar es la obra de Pedro Barrantes Maldonado, Illustraciones de la Casa de Niebla (1541-1573), de obligada lectura a la hora de trazar la historia de los Medina Sidonia. Este documento tiene pretensiones de crónica histórica pero a juzgar por la manera en que describe los personajes y analiza los hechos, se observa que hay un propósito didáctico de fondo. Este compendio de modales presumiblemente iría dirigido a las clases altas pero también al pueblo llano (Inés, 2000:177). Mediante la reproducción del comportamiento modélico de las damas De Niebla (el virtus) se pretende que

33 Ibídem «[...] sirvan de fincas et asy [ileg.] que se necesitassen para pagar las deudas que faltara [...]».

34 Sobre este tema se recomienda la lectura de Segura González, Wenceslao (2002): «Las varias María Coronel» Aljarama, Año XII. Núm 46. http:/ / www.tarifaweb.com/aljaranda/num46/num46.htm

35 La crónica más remota es la escrita en el siglo XVI por Pedro Barrantes Illustraciones de la Casa de Niebla. La referencia completa se detalla en el apartado Fuentes y Bibliografía. 
las mujeres nobles quieran parecerse a ellas en tanto a iguales y que las humildes imiten lo que para ellas es la posición social a que, por una parte están subordinadas, y por otra admiran y aspiran. Inés Carzolio (2000,145-192) analiza en sus trabajos la presencia de leyenda e historia en la redacción de Barrantes. Advierte de que el autor de las Illustraciones era un hombre renacentista que bebía de la épica clásica y medieval. Pese a todo, Pedro Barrantes afirmó en su obra haberse basado en la información documental y cronística del siglo XIII. No se debe olvidar que el propósito de estas crónicas nobiliarias como nos indica Inés Carzolio es la propaganda y legitimación de la nobleza (2000: 177).

Al igual que otros personajes históricos como Jimena Díaz, esposa de Rodrigo Díaz de Vivar, la literatura épica y su resurrección en el siglo XIX emborrona los aspectos biográficos y los confunde con elementos legendarios y literarios. Estos, por su parte, dan cuenta del uso que se hizo de las mujeres en la literatura durante estos años. A continuación, se presenta el análisis de otra obra dedicada a Doña María Alonso Coronel, escrita en 1792.

\section{La mujer heroica}

La mujer heroica. Esposa de Alonso Pérez de Guzmán el Bueno, María Alonso Coronel la cual se referirá en adelante como La mujer heroica, es un melólogo escrito por Joaquín Barón y Domingo en 1792 dedicado al duque de Arión.

Cabe una aclaración sobre el término «melólogo». Guijarro Ceballos lo define como la «agrupación de obras dramáticas breves con intervalos de música instrumental» y lo clasifica como un subgénero del melodrama (2011: 42). Sobre Joaquín Barón Domingo, el autor de la obra, se conocen pocos datos. Se sabe que vivió entre la segunda mitad del siglo XVIII y la primera del XIX. Era abogado del Colegio de la Corte y pertenecía a la Academia de Pastores del Manzanares donde ejercía su afición de escritor con el sobrenombre Delio. Al parecer Barón habría caído en desagrado del Rey y de su familia por el ejercicio de la cómica, lo cual podría explicar la falta de datos sobre la vida del escritor. El melólogo al que nos referimos fue, de hecho, interpretado por su mujer María Coleta en la casa del duque de Arión.

La obra está compuesta de: una dedicatoria, un prólogo, el argumento y dieciséis secciones entre las cuales se interpretan piezas de música breves. La dedicatoria, como ha sido ya referido, va dirigida a don Manuel Antonio Fernández de Córdoba y Pimentel, duque de Arión. A continuación se presenta el prólogo en el que el autor perfila y justificar elementos como el estilo que ha utilizado o la razón por la que ha escrito la obra. Mención aparte merece una declaración que hace al respecto: "en él [el Drama] no verás otra que la contraposición de afectos que sufre la muger que te presento, y que a mi parecer son propios de su situación $»^{36}$. Es interesante este aspecto porque el melodrama da voz a las reflexiones de una mujer, pero sin

36 Biblioteca Nacional de España [en adelante BNE] T/12225: «La muger heroyca, esposa de Alonso Pérez de Guzmán el Bueno, Doña María Alonso Coronel : Drama unipersonal compuesto por Don Joachîn Barón y Domingo, con música en sus intervalos y dedicado al excelentísimo señor duque de Arión» [en adelante «La muger heroyca»] 1792, sin foliar. 
olvidar que quien lo escribe es un autor masculino. El dicho prólogo irá seguido del argumento, en que se sitúa históricamente la obra: «Hallándose Alonso Pérez de Guzmán el Bueno, Alcayde de Tarifa, en tiempo en que tenían puesto sitio los Moros, hicieron prisionero a su hijo» ${ }^{37}$. Como ya se ha desarrollado, en 1294 el rey Sancho IV pide ayuda a Alfonso Pérez de Guzmán para la defensa de Tarifa que acaba con la victoria de Sancho y la muerte del benjamín de la Casa Guzmán Coronel. Lo que sigue al argumento es ya el comienzo de la obra en sí. Al tratarse de un melólogo el texto está dividido en secciones interrumpidas por una breve interpretación musical.

Inicia el drama cuando Doña María lee una carta de su marido y se entera de la suerte de su hijo. A partir de ese momento, dudará entre ir ella misma a socorrerlo o no. Conforme va reflexionando en su monólogo se disgusta de su propia cobardía refiriéndose a la valentía como un atributo varonil: «¿Dónde está mi valor, mi resistencia y el varonil esfuerzo que he tenido?» ${ }^{38}$. Esta evocación a los «varoniles esfuerzos» la llevan a apelar directamente a su marido «mi esposo, mi Guzmán» ${ }^{5}$. En este momento parece que toma la decisión de no hacer nada y depositar la responsabilidad de la acción en su marido, confiando en que él salvará a su hijo "Ya tal vez á estas hora, sí, seguro habrá facilitado y conseguido rescatar á mi prensa de mi vida» ${ }^{39}$. Pero reflexiones la conducen a estimar que «un hombre que procede tan indigno [su marido, Guzmán] es quien tiene la culpa de tu muerte» ${ }^{40}$. De hecho se rebela contra él y le desea la muerte.

Tras este breve trance de furia hacia su esposo e intentando ponerse en su lugar discurre en que la acción de Guzmán ha sido noble «¿No será de inmortal elogio digna la acción de mi Guzmán si bien la miro? No sería traidor á su monarca, a su Dios, a su patria, á sus amigos, entregando Tarifa a los alárabes por conservar la vida de su hijo?» ${ }^{41}$. Este es un episodio de gran relevancia en la obra, ya que por primera vez se hace referencia a la heroicidad, y se hace en referencia al marido de la protagonista «Y Alonso Pérez de Guzmán, mi esposo, es en el mundo todo distinguido por $s u$ valor, lealtad, nobleza, esfuerzo heroycidad» ${ }^{42}$. Concurre con esas reflexiones sobre los loables valores de su marido en los siguientes párrafos, contraponiéndolos a su cobardía y flaqueza. Con todo, admite que hace bien en ser débil y llorar la muerte de su hijo porque de no hacerlo contravendría las leyes de la naturaleza: «Que sería madre muy ingrata si á la naturaleza los oídos le cerrara» ${ }^{43}$.

Termina el melólogo reconociendo la valentía y el servicio que le han demostrado su marido, por haber tomado la justa decisión y su hijo, por haberse convertido en mártir de la fe cristiana. "Ya que tu padre, revestido, para resolución tan virtuosa, de impulso celestial ha conseguido el triunfo más heroyco con tu muerte» ${ }^{44}$ Acaba dando

37 Idem.

38 BNE T/12225: «La muger heroyca» 1792, párrafo 4, sin foliar.

39 Ibídem, párrafo 5 , sin foliar.

40 Ibídem, párrafo 8 , sin foliar.

41 Ibídem, párrafo 9, sin foliar.

42 Ibídem, párrafo 10, sin foliar.

43 Ibídem, párrafo 14, sin foliar.

44 Ibídem, párrafo 17, sin foliar. 
gracia a Dios «Oh señor soberano, justo y pío, pues vuestra mano fuerte y poderosa tiene hoy a bien quitarme el tierno hijo, que me dio en otro tiempo compasiva, sed por siempre loado y bendecido» ${ }^{45}$. Vuelve a hacer referencia a la heroicidad, otra vez vinculada a su marido.

Tras este breve recorrido por el texto dramático pueden extraerse algunas consideraciones al respecto. La primera y la que más llama la atención es la concerniente a la heroicidad. Por un lado el título del melólogo es «La mujer heroica», cabría pues esperar que la protagonista llevara a cabo algún tipo de acción trascendente y sin embargo las dos únicas veces que se menciona la heroicidad se hace en referencia al esposo. Además la acción sitúa al personaje en todo momento sentada en su casa.

Puede parecer que el drama haya sido escrito para aclamar - y en cierta manera justificar- la acción de Alonso Pérez de Guzmán más que para elogiar la figura de María Alonso Coronel. La respuesta a esta incógnita pasa por reconocer un rasgo clave del teatro del XVIII: la dramática del diecisiete es una literatura abierta a la demostración de los sentimientos (Angulo, 2006: 472). Por esta razón, muchos autores utilizaron la figura de la mujer protagonista porque entendían que el sexo femenino estaba más inclinado a la sensibilidad. El llanto era signo de debilidad; mientras en la mujer era comprensible y conmovía al público, el del hombre era inadmisible. Este tipo de literatura es escrita por hombres y tiene pretensiones pedagógicas por ello presenta a mujeres de gran trascendencia en la historia de España. En ellas plasma una feminidad doméstica, el ideal de mujer virtuosa, de conducta pudorosa y privada de cualquier tipo de sensualidad con las que quiere influir a su audiencia. Se trata pues de un género, el melólogo, en que las mujeres «siendo protagonistas de las narraciones, desempeñan papeles semipasivos» (Angulo, 2006: 474). Son meras observadoras de las acciones que desarrollan los varones, usualmente de su propia familia, cumplen con el propósito de dulcificar y justificar las decisiones que estos toman, a menudo controvertidas, y que tienen que ver con la gloria de la nación.

Se considera heroica a María Alonso Coronel en tanto que se ciñe a su rol de esposa y madre abnegada. La protagonista, lejos de comportarse como es debido, se permite renegar de su marido y llorar la muerte de su hijo. La acción se justifica en su flaqueza, propia de su sexo. Sin embargo termina por vencer las trabas sensibleras características de las mujeres, las que las alejan de los valores masculinos de entereza y justicia. Ahí es cuando se convierte en heroína, cuando comprende que hace mal en proceder de esa manera tan rebelde, «se vence a ella misma» y vuelve a convertirse en la esposa sumisa, obediente y temerosa de Dios que se espera de ella; llegando, como se describe al final de la obra, a dar gracias a Dios por el sacrificio de su hijo.

Sobre este ideal de mujer escribe D'Assunção Barros. El autor desarrolla en su artículo la imagen de heroicidad femenina que, como indica, solo se entiende si se atiende a la visión que se tenía de la mujer en la época «enfrentavam consideráveis 
limitações (...) para se mostrarem como agentes histórico-sociais capazes de conduzir as próprias vidas em um sistema que as via freqüentemente como meras reprodutoras e mesmo como objetos de troca, através do casamento, nas relações interfamiliares e interlinhagísticas ${ }^{46}$ (D’Assunção, 2015: 105). En este caso el autor hace referencia a la imagen de la mujer medieval en la literatura. La literatura es una crónica fiel de las estructuras socioculturales de la época en que es escrita y por ello gran aliada de la historiadora o historiador. El hecho de que coincida la imagen femenina en época medieval en la que vivió Doña María y la de finales de la época moderna, en que fue escrita La mujer heroica, es muestra irrefutable de que a lo largo de la historia las mujeres han estado, salvo en contadas excepciones, sujetas a un arquetipo rígido de feminidad y subordinadas a la tutela del padre, hermano o marido. No en vano, la teoría feminista denomina a este sistema "patriarcado». Es esta ideología que comienza su andadura a finales del XIX, la que primero criticó la perpetuidad de este modelo de mujer.

Con todo cabe destacar, a sabiendas de que la mujer en esta representación es un títere de las consideraciones de un autor masculino y de que responde a las características formales de este tipo de género dramático, que en ciertos momentos la protagonista de la historia sí se permite la licencia de rebelarse contra lo establecido, de alzar la voz en contra de una situación que considera injusta. Así, no tiene ningún reparo en contestar la acción de su marido «¿Di, bárbaro, tirano abominable, a que fiera la saña le has pedido para ver practicar á tu presencia tan triste y lastimoso sacrificio?» ${ }^{47}$ Es más, llega a decir que lo matará «Tu muerte es sola la que puede purificar tan grave afrenta como la que produce el parricidio: yo por mi mano solicito quitar ese borrón de tu linaje. Y con este puñal[...]» ${ }^{48}$. Inmediatamente después exclama «iPero qué digo!» Arrepintiéndose de lo dicho y reafirmando su apoyo a la acción de Alonso Pérez de Guzmán. Esta parte se puede considerar como una contraposición, común en la literatura, de los dos modelos femeninos que traspasan el prototipo de mujer ideal (María) a mujer concreta (Eva), de mujer sumisa a mujer sometida (D'Assunção, 2015: 132).

En efecto, María Coronel al igual que el Libertador de Tarifa, pasó a la historia mitificada como la heroína «en cuanto a sus virtudes morales» (Segura, 2002: 4). Además, anterior al pasaje que acaba de comentarse y que inspiró a Barón Domingo en la composición de su monólogo, los cronistas de diversas épocas hicieron todos referencia a su episodio con el tizón. De hecho, en su tumba sita en el Monasterio de San Isidoro del Campo (Santiponce), a cada lado del blasón familiar se colocaron sendos tizones en recuerdo del suceso. Se alude en esta ocasión a otra de las virtudes de la mujer ideal: su castidad y el veto a cualquier atisbo de sexualidad que se desviara de su función reproductiva dentro del seno familiar (Angulo, 2006: 473).

46 «Se enfrentaban a considerables limitaciones [...] para mostrarse como agentes histórico-sociales capaces de conducir sus propias vidas en un sistema que las veía frecuentemente como meras reproductoras e incluso como objetos para el trueque a través del matrimonio, de las relaciones interfamiliares y de las relaciones dentro de los linajes». Traducción propia.

47 BNE T/12225: «La muger heroyca» 1792, párrafo 8, sin foliar.

48 BNE T/12225: «La muger heroyca» 1792, párrafo 9, sin foliar. 


\section{Conclusiones}

Citando a la medievalista Covadonga Valdaliso ${ }^{49}$, la frontera entre Historia y Literatura que en un principio parece sencilla de separar se diluye cuando emprendemos el estudio de los textos. La tarea de las historiadoras e historiadores se acompleja cuando se enfrenta a textos que en su origen fueron obras literarias y que a día de hoy siguen constituyendo un tesoro literario, pero también histórico. A lo largo de este artículo se ha estudiado la figura de María Alonso Coronel, fundadora y matriarca de uno de los linajes más poderosos y prósperos de la historia medieval y moderna hispánica. El título de marquesa de Medina Sidonia lo llevó hasta 2008 otra mujer, Luisa Isabel Álvarez de Toledo, conocida como la Duquesa Roja por su abierta subversión contra el régimen franquista así como por su discurso pluralista y demócrata.

En el presente artículo se ha tratado de seguir la máxima expuesta también por Valdaliso: cualquier obra literaria del pasado es una fuente histórica en el presente. En este caso se enfrenta una dificultad añadida: el texto literario se escribe con más de cuatrocientos años de diferencia desde la muerte de la protagonista. Sin embargo, resulta si cabe todavía más interesante porque se le van a atribuir a unos hechos acontecidos en el siglo XIII la mentalidad del autor que lo escribe en plena Ilustración, momento en que ya se ha despertado la conciencia de género en algunas personas y que sin duda es el pistoletazo de salida de los estudios feministas y de género. Para que el análisis fuera más completo se han cotejado la obra literaria de Barón y Domingo con fuentes históricas documentales, a saber: el testamento de María Alfonso Coronel y dos privilegios de Fernando IV; y obras a medio camino entre la historia y la literatura, como las Ilustraciones de la Casa de Niebla de Barrantes Maldonado. Así, del análisis sistemático y contrastado se extraen las siguientes conclusiones.

Como ya referido, la literatura es una fuente histórica que debidamente equiparada con documentación de la época supone un recurso válido y muy enriquecedor en el discurso histórico. Un discurso que tradicionalmente ha marginado de manera sistemática a las mujeres de su narración. La irrupción de la teoría y praxis feminista empieza a revisar este relato hijo de una sociedad que solo da voz a varones occidentales blancos, heterosexuales, de mediana edad y de una clase social media o alta. Así rescatan del silencio la vida de algunas mujeres cuyo protagonismo en la historia fue fagocitado en su momento por el apellido familiar. Es el caso de María Alfonso Coronel, a la cual solo se le recuerdan «gestas» propias de su género como su maternidad, su castidad y su fe cristiana sin deparar en la excelente e impoluta gestión que tuvo para con el patrimonio de su Casa. Suyo fue el mérito de dar a luz a uno de los linajes más notables de España, de engrandecerlo hasta límites insospechados para la época y de afianzar su poder e influencia para que el título ducal Medina Sidonia, que tiene su germen en el señorío de Sanlúcar, haya sobrevivido hasta hoy. Sin desprestigiar la labor que pudo realizar como madre, esposa y fiel

49 Valdaliso Casanova, Covadonga (2005). La referencia completa se detalla en el apartado Fuentes y Bibliografía. 
cristiana, resulta sesgado y vejatorio reducir a la que Miguel Ángel Ladero ha referido como la «matriarca sevillana» ${ }^{50}$ al compendio de virtudes que se le atribuía en la obra de Barón Domingo y otros autores.

La tarea de la historiadora decidida a redactar una historia plural en que se dé voz a la totalidad de sus protagonistas es de suma complejidad. La pretensión de hacer una historia de estas características, fiel a los hechos históricos que se plasman en las fuentes históricas tropieza a menudo con la inexistencia de fuentes o en caso de que las haya, siempre o casi siempre relacionadas con los roles que supuestamente debían cumplir las mujeres. Al hilo de estas dificultades, Serra-Santana y Birriel Salcedo proponen metodologías para elaborar historia de las mujeres tomando como campos de estudio principales la demografía y la familia ${ }^{51}$. Como problema añadido debe tenerse en cuenta la diferencia de mentalidades cuando se establece el diálogo historiador-historia. Como defiende Riviera, es posible respetar el hecho histórico y a la vez narrarlo desde un enfoque feminista sin caer en el anacronismo y el ahistoricismo si se aplican metodologías de análisis adecuadas (1992: 140).

Con todo, no es fácil encontrar documentación histórica referente a mujeres, por eso podemos suponer que cuando aparece alguna de ellas en algún texto hubo de haber sido muy notable en la época. Tanto si seguían el arquetipo Eva o María su comportamiento era expuesto con afán didáctico para las siguientes generaciones, condenando la acción de las evas y alabando a las marías. Sobre las mujeres que obraron bien - para la mentalidad de la época- acatando y actuando según lo establecido, se puso énfasis en resaltar sus virtudes, aquellas que las hacen heroicas, como ocurre a la primera Señora de Sanlúcar. Aunque en este caso y a la luz de lo descrito en este artículo sí se puede llegar a la conclusión de que María Alfonso Coronel realmente fue, si no heroína, una mujer de negocios brillante.

\section{Bibliografía}

Álvarez De Toledo, Luisa Isabel (1992): «La mirada hacia la historia» Aljaranda (Historia), n. ${ }^{\circ} 46$, pp. 12-18.

Angulo EgeA, María (2006): «Virtuosa, casta y heroica. La mujer española en el melólogo del XVIII» Revista de Literatura, Vol. LXVIII, n. ${ }^{\circ}$ 136, pp.471-488.

Anderson, Bonnie y Zinsser, Judith (2000): «Mujeres de los Castillos y los señoríos. Guardianas de la tierra y el linaje» en Anderson, Bonnie y Zinsser, Judith (2000): Historia de las mujeres: una historia propia. Crítica, barcelona, Vol I, IV parte

50 Consultar Ladero Quesada, Miguel Ángel (2002): «Doña María Alfonso Coronel: matriarca sevillana (1267-1331)» Poder y sociedad en la Baja Edad Media hispánica: estudios en homenaje al profesor Luis Vicente Díaz Martín, Vol. 1, pp. 427-460.

51 Consultar Birriel Salcedo, Margarita Ma (1992): Nuevas preguntas, nuevas miradas. Fuentes y documentación para la historia de las mujeres (siglos XIII-XVIII). Feminae, Universidad de Granada (Seminario de Estudios de la Mujer), Granada, pp. 139-155. 
BirRIEl SAlCEdo, Margarita Ma (1992): Nuevas preguntas, nuevas miradas. Fuentes y documentación para la historia de las mujeres (siglos XIII-XVIII). Femiae, Universidad de Granada (Seminario de Estudios de la Mujer), Granada, pp. 139-155.

Cotarelo y Mori, Emilio (20091902): Isidoro Máiquez y el teatro de su tiempo. Publicaciones de la ADE, Serie: Teoría y Práctica del Teatro, n. ${ }^{\circ}$ 31, Madrid.

D’Assunção BARros, José (2015): «Imagens da realeza, heroísmo e mulher em una narrativa medieval ibérica, A Lenda de Gaia» Boletín galego de literatura, n. ${ }^{\circ} 47$, pp.105-134.

GALÁN PARra Isabel (1988): «El linaje y los estados señoriales de los duques de Medina Sidonia a comienzos del siglo XVI» La España Medieval, n. ${ }^{\circ}$ 11, Publicaciones Universidad Complutense de Madrid, Madrid.

Guijarro Ceballos, Javier (2011): «El «melólogo». El nombre de un género sin nombre». Anuario de Estudios Filológicos, Vol. XXXIV, pp. 39-52. Consulta: https: / / dialnet.unirioja.es/servlet/articulo?codigo=3849889

InÉs CARzolio, María (2000): «Mujeres medievales en la crónica renacentistas: las damas de la Casa de Niebla» La Aljaba, Segunda Época, Vol. V, pp.175-192.

Ladero Quesada, Miguel Ángel (2002): «Doña María Alfonso Coronel: matriarca sevillana (1267-1331)» Poder y sociedad en la Baja Edad Media hispánica: estudios en homenaje al profesor Luis Vicente Díaz Martín, Vol. 1, pp. 427-460

López Beltrán, María Teresa (coord.) (1999): De la edad media a la moderna: mujeres, educación y familia en el ámbito rural y urbano. Atenea, Estudios sobre la mujer, Universidad de Málaga, Málaga.

Marchant Rivera, Alicia (2013): Doña María Fernández Coronel, aya de la reina María de Molina: creadora del lenguaje histórico en la Edad Media. Servicio de publicaciones de la Universidad de Málaga (RIUMA), Málaga.

Nastasescu, Diana (2016): La política matrimonial de los Reyes Católicos. Repositorio Biblioteca Universitat Jaume I. URL:

http:/ / repositori.uji.es/xmlui/handle/10234/164904

Peñafiel RAmón, Antonio (2001): Mujer, mentalidad e identidad en la España moderna (siglo XVIII). Servicio de publicaciones de la Universidad de Murcia, Murcia.

Riviera GARretas, Margarita (1992): «Textos de mujeres medievales y crítica feminista contemporánea» en Birriel Salcedo, Margarita $\mathrm{M}^{\mathrm{a}}$ (1992): Nuevas preguntas, nuevas miradas fuentes y documentación para la historia de las mujeres (siglos XIIIXVIII). Femiae, Universidad de Granada (Seminario de Estudios de la Mujer), Granada, pp. 139-155.

Segura GonzÁlez, Wenceslao (2002): «Las varias María Coronel» Aljaranda (Historia), n. ${ }^{\circ} 46$, pp. 4-6.

Segura Graiño, Cristina (1992): La voz del silencio I (siglos VIII-XVIII). Asociación cultural Al Mudayna, Madrid.

VAldaliso CASANOva, Covadonga (2005): «Da cronística medieval como obra literária y la literatura medieval como fuente histórica» Literatura e Historia. Comunicações Relações teóricas e metodológicas. Servicio publicaciones de Universidade Aberta, Lisboa. pp: 115-125. 


\section{Fuentes}

\section{Manuscritas}

Archivo Casa Medina Sidonia, Cádiz

Fondo Medina Sidonia

AGFCMS, leg. 910, doc. 05: Testamento de María Alfonso Coronel.

AGFCMS, leg. 888, doc. 09: Privilegio Real de Fernando IV concediendo a Alonso Pérez de Guzmán, I señor de Sanlúcar de Barrameda, la villa de Vejer de la Frontera a cambio de 56.000 doblas de oro que el Rey le debía y las villas de Zafra y la Falconera, situadas en Badajoz.

AGFCMS, leg. 909, doc. 03: Privilegio Real de Fernando IV concediendo a Alonso Pérez de Guzmán, su vasallo y alcaide del castillo de Tarifa, la villa de Sanlúcar de Barrameda con todos sus pobladores, términos, pertenencias, pechos y derechos.

Biblioteca Nacional de España, Madrid.

Mss/3299 - Barantes Maldonado, Pedro (1541): Ilustraciones de la Casa de Niebla: en que se trata del principio y origen de los Guzmanes duques de Medina Sidonia, marqueses de Casaza de Pedro Barrantes Maldonado.

Real Academia de la Historia

Colección Salazar y Castro.

9/134: Ilustraciones de la Casa de Niebla, Pedro Barrantes Maldonado (1541).

\section{Impresas}

Real Academia de la Historia, Madrid.

16/2324 (b) - Cano y Cueto, Manuel (1848): Doña María Coronel.

Biblioteca Nacional de España, Madrid.

T/12225 - Barón y Domingo, Joaquín (1792): La muger heroyca, esposa de Alonso Pérez de Guzmán el Bueno, Doña María Alonso Coronel: Drama unipersonal compuesto por Don Joachîn Barón y Domingo, con música en sus intervalos y dedicado al excelentísimo señor duque de Arión».

Recibido el 9 de junio de 2020

Aceptado el 1 de junio de 2021

BIBLID [1132-8231 (2021): 149-164] 